\section{ATIVIDADE físICA E JOGOS OLIMPICOS: REFLEXÕES A PARTIR DE LONDRES 2012 E RIO 2016*}

\author{
Billy Graeff, Paul Bretherton e Joe Piggin \\ Tradução de Gilberto Stam
}

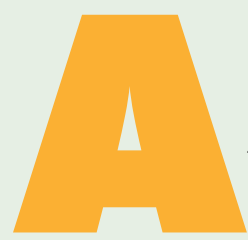

pós a inclusão do conceito de "legado" na Carta Olímpica em 2002 (1), os países anfitriōes dos Jogos Olímpicos passaram a demonstrar uma expectativa crescente de que o evento deixasse um legado social positivo para a comunidade que o recebe. Cada vez mais, a resposta a tal expectativa baseia-se, pelo menos em parte, no entendimento de que o evento tem a capacidade de aumentar a prática de atividade física junto à população do país anfitrião. Isso se deve à suposição de que as disputas esportivas de alto rendimento, exibidas durante os Jogos, irão incentivar - ou "inspirar" - mais pessoas a ter uma prática regular de atividades físicas e esportivas.

Este artigo faz uma análise da política e da retórica de legado para a prática de atividade física, empregada em relação aos Jogos Olímpicos de Londres, em 2012, e do Rio de Janeiro, em 2016 as duas primeiras cidades anfitriãs dos Jogos Olímpicos de Verão a serem selecionadas após a incorporação formal do conceito "legado" na Carta Olímpica de 2002. A interação entre os fatores colocados acima e os respectivos contextos sociais e culturais no Reino Unido e no Brasil oferecem uma perspectiva útil para analisar um aspecto cada vez mais proeminente das razōes contemporâneas para sediar os Jogos Olímpicos -, bem como as implicaçôes mais amplas que o caso do legado de prática de atividade física pode ter para todas as formas de legado que são enfatizadas pelos anfitriōes desses eventos.

\section{JOGOS OLÍMPICOS DE LONDRES 2012: "INSPIRAR UMA GERAÇÃO"}

Citando Londres 2012 como a "melhor oportunidade em uma geração para encorajar as pessoas a serem mais ativas fisicamente" (2), os planos oficiais do governo do Reino Unido para o legado dos Jogos Olímpicos afirmavam que:

A primeira prioridade dos Jogos é fazer do Reino Unido um líder mundial nos esportes. Esperamos que as pessoas se tornem cada vez mais ativas, com o objetivo de vermos dois milhōes de pessoas se tornarem mais ativas até 2012, através de investimentos focados em nossa infraestrutura esportiva e melhor apoio e informação para os que querem praticar atividade física (3).

No entanto, Girginov e Hills alertam que para obter um aumento de participação nessa escala seria necessário lidar de maneira bem sucedida com "estruturas sociais profundamente enraizadas" (4) e, de fato, evidências acadêmicas indicam, cada vez mais, que essas metas são pouco realistas. Vários autores, por exemplo, concluíram que não há evidências suficientes para corroborar que Londres 2012 tenha sido um meio de promover a prática esportiva ou atividade física (5-7), e que qualquer tentativa de atingir esse objetivo deveria passar por um esforço coordenado maior em que os Jogos representassem parte de uma estratégia mais ampla de prática esportiva e atividade física (7). Mesmo para chegar perto do aumento pretendido de dois milhōes de pessoas mais ativas em 2012, seria necessário um esforço coletivo fenomenal, tanto por parte dos organizadores do evento quanto por uma gama considerável de organizaçōes locais, esportivas e de saúde.

Tal esforço não se concretizou, e a diretora executiva de Esportes da Inglaterra, Jennie Price, anunciou, em 2011, o abandono das metas de participação estabelecidas em 2008:

Estou muito decepcionada porque temos somente 111.000 pessoas a mais praticando esportes quando contávamos com 1 milhão, mas temos de ser realistas sobre o clima em que estamos trabalhando. Jeremy Hunt [o secretário da Cultura] já disse que não acredita que a meta de 1 milhão seja a medida certa de participação imediatamente após os Jogos Olímpicos, mas acho que teremos uma boa medida de participação após um ano ou dois, e teremos um salto por causa dos Jogos Olímpicos (8).

$\mathrm{O}$ argumento de Price toca em dois fatores importantes, citados acima, para o fracasso do legado da participação em massa da população. Em primeiro lugar, a menção ao "clima" se refere à crise financeira no final dos anos 2000, com o pressuposto de que ela teve um impacto direto sobre o acesso ao esporte e à atividade física. Em segundo lugar, o questionamento da escala de tempo na qual as metas de participação de 2008 foram estabelecidas destaca uma questão mais ampla da avaliação do legado olímpico, que para alguns autores requer um período de 15 a 20 anos para ser medido satisfatoriamente (9).

Com o abandono oficial dos objetivos de participação em massa de 2008, o foco da proposta de legado esportivo foi restringido aos jovens. Mais uma vez, o contexto econômico mais amplo teve um papel central na explicação dada pelo então secretário de Cultura Jeremy Hunt:

Eu acho que é razoável perguntar se, com recursos tão limitados, focar na participação de adultos seria um uso adequado do dinheiro dos contribuintes, quando na verdade o que queremos é fazer com que jovens adquiram um hábito para a vida toda (10).

Esse raciocínio logo foi formalizado em janeiro de 2012, quando o Departamento de Cultura, Mídia e Esporte (DCMS, na sigla em inglês) publicou seus novos planos para o legado esportivo. O objetivo era usar Londres 2012 para "inspirar a nação e ajudar os jovens, 
particularmente, a começar um hábito esportivo para a vida" e assim "fazer cumprir a promessa original" (10) que Lord Coe e a equipe de candidatura haviam estabelecido em 2005. Essa promessa deveria ter sido cumprida por meio de uma abordagem que promovesse ligações na base esportiva entre escolas e clubes e um sistema de cooperação com as organizações esportivas nacionais. Embora esse foco na juventude e no futuro possa parecer louvável, uma abordagem de longo prazo dessa natureza coloca problemas significativos para a prestação de contas, responsabilização e avaliação frente aos compromissos assumidos. Como observado por Wellings, Datta, Wilkinson e Petticrew (11), determinar que medidas políticas baseadas nos Jogos Olímpicos podem ser avaliadas como tendo feito uma diferença mensurável é algo complexo, e qualquer avaliação conclusiva se revelará excepcionalmente difícil.

A confusão se torna ainda mais evidente quando se contrasta essa ênfase da política do DCMS com as declaraçōes públicas sobre os dados do governo. Por exemplo, no mesmo mês em que esse foco no esporte juvenil foi formalizado, o primeiro-ministro britânico David Cameron afirmou que:

O país inteiro pode se beneficiar do legado dos Jogos por causa da inspiração que esses jogos trarão para jovens e idosos em todo o país para que se envolvam, façam exercício, aprendam a nadar, aprendam a mergulhar, e tudo o mais (12).

O fato de que Cameron contradisse a estratégia desenvolvida pela DCMS demonstra que é difícil ver a estratégia global de legado de participação sem suspeita. De forma mais ampla, a necessidade de que o legado olímpico seja coordenado entre todas as entidades organizadoras do evento, bem como um governo anfitrião inerentemente caprichoso, demonstra a natureza problemática de todo o processo.

Além dessas preocupaçóes, é importante reconhecer que o governo anfitriāo pode mudar ao longo do período de preparação para sediar os Jogos. Em 2010, o governo do Partido Trabalhista, que tinha dirigido as etapas iniciais de candidatura e planejamento, foi substituído por uma coalizão conservadora. Embora a abordagem do governo para os Jogos tenha sido, em muitos aspectos, consistente com a de seu antecessor, uma diferença notável foi sua ênfase na redução da despesa pública, procurando transferir responsabilidades para os setores privado e de voluntariado. Em termos do legado de prática esportiva e atividade física isso ficou claro, de forma mais direta, pela intenção do então secretário de Educação, Michael Gove, de reduzir o financiamento para parcerias esportivas com escolas - embora, eventualmente, isso não tenha sido cumprido (13). Mais amplamente, a defesa feita pela coalizão conservadora do papel dos negócios na sociedade teve implicações importantes para os serviços de saúde:
A força de um acordo reside na diversidade de organizaçôes que ele reúne - setor público, comercial, não-governamental e acadêmico - para determinar as coisas que os negócios podem fazer para acelerar o progresso em direção às metas de saúde pública (...) Simplificando, organizações comerciais podem alcançar os indivíduos de uma forma que outras organizaçôes, governo incluso, não conseguem (14).

Esta atitude em relação ao papel dos negócios na promoção da saúde é consistente com a convicção crescente de que o potencial social do esporte deveria ser explorado por projetos de responsabilidade social empresarial (RSE) (15). Em relação ao legado de prática esportiva e atividade física de Londres 2012, vários patrocinadores olímpicos - sob a supervisão do Comitê Organizador dos Jogos Olímpicos e Paralímpicos de Londres (Locog, na sigla em inglês) - coordenaram iniciativas sociais envolvendo esporte, saúde ou atividade física em várias formas. A National School Sport Week do banco Lloyds TSB, o Spots vs Stripes da Cadbury (marca de chocolate), e a parceria da Coca-Cola com os StreetGames são exemplos de eventos locais que priorizaram a participação de populações específicas, como crianças em idade escolar ou comunidades carentes. Outras iniciativas, como Champions of Play do McDonald's e Design my Break da GE também pretendiam contribuir para a saúde ou a consciência sobre atividade física, incentivando os jovens a se envolverem mais com esses problemas, enquanto a Adidas instalou aparelhos para exercícios chamados adiZones em parques locais para os residentes da região usarem de graça.

Após a conclusão dos Jogos em agosto de 2012, o prefeito de Londres, Boris Johnson, declarou:

Dirão que não haverá aumento da participação esportiva e nenhum benefício econômico, e que não teremos sucesso na recuperação do leste de Londres. Bem, que todos se lembrem apenas de uma coisa. Foi provado que esses céticos olímpicos estavam redondamente enganados sobre os Jogos. Será provado que eles estão errados também sobre o legado (16).

O entusiasmo de Johnson tipificava tanto o discurso da mídia dominante durante e logo após os Jogos, quanto a maneira com que esse tom de celebração era tomado, frequentemente, como evidência de que os resultados "positivos" do legado, como o aumento da participação no esporte e atividade física seria um resultado natural. No entanto, em 2013, o então ministro do esporte Hugh Robertson já adotara uma postura mais cautelosa:

Acho que vamos precisar de pelo menos cinco anos e, mais provavelmente, uma década, antes que possamos fazer um julgamento definitivo sobre o sucesso do legado esportivo de Londres 2012, mas os fundamentos são fortíssimos. A reputação da Grã-Bretanha no esporte mundial certamente se transformou. Em todo lugar que passei, desde Londres 2012, as pessoas felicitaram este país por ter hospedado jogos maravilhosos (17). 
Embora o reconhecimento de Robertson de que é necessária uma avaliação de mais longo prazo para tornar consistente as recomendações acadêmicas para a avaliação do legado olímpico (9), nota-se que ele confunde aqui essa questão com o reconhecimento internacional recebido pelo Reino Unido para a realização dos Jogos. No mesmo documento é observado que, apesar de uma diminuição recente, o número de pessoas que praticavam esporte pelo menos uma vez por semana aumentou em 1,4 milhão em relação a 2005, quando Londres foi escolhida como sede para 2012 (18). "Tendências subjacentes positivas” (19) também são notadas na participação de grupos como jovens, mulheres e deficientes. Embora essas estatísticas possam parecer positivas, deve-se notar, em primeiro lugar, que a comparação com 2005 é limitada, dado que nenhuma tentativa formal para aumentar a participação foi anunciada até 2008. Em segundo lugar, o foco singular na prática esportiva aqui contradiz o compromisso assumido anteriormente de incentivar, simultaneamente, a prática mais ampla de atividade física. Em terceiro lugar, finalmente, qualquer aumento medido até 2013 teria de ser comprovadamente mais sustentável do que os aumentos de curto prazo na participação que têm sido observados em eventos anteriores (7).

Ainda que a discussão atual retrate um objetivo de legado que foi defendido entusiasticamente por representantes do governo e do Locog a partir da fase de candidatura, evidências empíricas mostram que, até agora, o progresso genuíno tem sido insignificante, e que as primeiras projeçôes não serão cumpridas. Além disso, a natureza pontual dos Jogos, com a rápida dissolução do Locog e troca subsequente de importantes ministros governamentais, sugere que a responsabilidade por seu fracasso, em última análise, nunca será estabelecida. Isso não significa que um aumento sustentado e tangível de participação no esporte e atividade física através dos Jogos Olímpicos não seja possível, mas que qualquer tentativa de provar o contrário vai exigir um esforço muito mais abrangente e coordenado do que foi comentado aqui em relação a Londres 2012.

RIO 2016: É A VEZ DO BRASIL Em contraste com os objetivos estabelecidos para Londres 2012, a atividade física não era, em geral, uma prioridade para os governos brasileiros (as esferas federal, estadual e municipal estavam envolvidas com candidatura e organização) em relação aos Jogos Olímpicos de 2016 e seu processo de candidatura - uma vez que a ênfase foi colocada, desde o início, no potencial dos Jogos para melhorar o desenvolvimento socioeconômico. Antes da votação final, em que o Rio foi finalmente escolhido como sede dos Jogos de 2016, o então presidente Luiz Inácio Lula da Silva afirmou ao Comitê Olímpico Internacional que os Jogos Olímpicos deveriam ser trazidos para a América do Sul pela primeira vez (20). Ele ressaltou que tal decisão iria corrigir uma distorção histórica e que ajudaria no desenvolvimento econômico do país e até mesmo do continente (21). Assim, para aqueles que seguem a economia política do esporte internacional, não foi surpresa que um país menos desenvolvido (conforme a definição da Organização das Nações Unidas) tenha sido escolhido como sede de um megaevento esportivo, após edições da Copa do Mundo de Futebol e dos Jogos Olímpicos serem alocadas no chamado Global South e em países pobres, por um período que parece ter começado antes dos Jogos Olímpicos de Atenas em 2004, e que se estende, pelo menos, até Qatar 2022. Além disso, pode-se argumentar que a candidatura do Brasil ajustou-se bem à narrativa dos Jogos Olímpicos como catalisadores para o desenvolvimento, e pode ter ajudado a candidatura a ser vitoriosa (22) num contexto em que isso havia se tornado parte do discurso oficial (1).

Em 2010, a candidata presidencial Dilma Rousseff enfatizou os aspectos que faziam parte de seus planos em relação ao esporte e aos Jogos Olímpicos - sem mencionar atividade física:

O compromisso que gostaria de reiterar aqui hoje é de fazer das Olimpíadas um instrumento para transformar o Brasil numa das maiores e melhores potências esportivas do mundo. Queremos um país com alto desempenho esportivo e social, que forme e treine atletas e ao mesmo tempo forme cidadãos com boa educação, formação, e emprego de qualidade (23).

Após sua eleição como presidente, Dilma Rousseff assinou uma medida provisória para liberar $\mathrm{R} \$ 1$ bilhão para o Plano Brasil Medalhas 2016 (24). O site do governo brasileiro mostra que não apenas $\mathrm{R}$ \$1 bilhão seria gasto na tentativa de garantir que o Brasil terminasse entre as 10 melhores nações na tabela de medalhas dos Jogos Olímpicos e entre as 5 melhores dos Jogos Paralímpicos do Rio 2016, mas que $\mathrm{R} \$ 2,5$ bilhōes seriam alocados para outros investimentos em esportes de alto rendimento (25).

Por sua vez, o dossiê de candidatura (26) salientou o fato de que o Brasil iria investir bilhões de dólares em um programa de aceleração de desenvolvimento, bem como na criação da Autoridade Pública Olímpica com uma Divisão de Transporte e Tráfego Olímpico e uma Divisão Olímpica para a Sustentabilidade. Assim, pode-se dizer que as questôes relacionadas com o déficit histórico em termos de desenvolvimento econômico e urbano, bem como em termos de aprimoramento da democracia, eram os mais importantes para o projeto Rio 2016.

O documento também acentua os aspectos comemorativos dos Jogos e se concentra na participação dos jovens e no potencial de transformação social através do esporte. Além disso, o documento revela que a estratégia seria investir na escola e esportes de alto rendimento, a fim de produzir um legado esportivo. Uma série de artigos publicados no site oficial do evento descreve como tal política seria desenvolvida (27-28). Reuniões com professores das redes municipais e estaduais foram as principais estratégias utilizadas pela Comitê Organizador dos Jogos Olímpicos no Rio de Janeiro (Cojo). No entanto, um estudo com os professores de educação física que vivem no Rio de Janeiro mostrou que eles "não tiveram quase nenhum conhecimento do Dossiê da Candidatura Rio 2016" ou de "legados soft" como os possíveis legados de atividade física (29). Além disso, os professores afirmaram que "nunca tinham sido informados de 
qualquer tentativa de aproveitar os Jogos Olímpicos para aumentar a prática esportiva ou em atividade física" (30). Outra estratégia para esse fim seria a realização de olimpíadas escolares (31).

Por outro lado, recursos consideráveis foram investidos na aquisição de equipamentos de alta tecnologia e na contratação de pessoal técnico na preparação de atletas brasileiros a fim de melhorar seus desempenhos nos Jogos realizados no Brasil (32). Essa foi uma forte tendência na área de financiamento do esporte, o que significa que ela foi especificamente orientada para esportes de alto rendimento, com ênfase em esportes olímpicos. Assim, pode-se dizer que, apesar da retórica, saúde e atividade física não são a maior prioridade de financiamento na área de esportes em geral e parece ocorrer o mesmo quando se trata de megaeventos esportivos (33) e que, aparentemente, o evento Rio 2016 foi consistente com essa tendência.

Juntamente com o discurso sobre o desenvolvimento econômico, social e urbano, alguma atenção foi dada pelos investidores para o potencial esportivo em termos de mobilidade social. Embora isso tenha sido parte do discurso oficial em relação a questões mais amplas (34), com referência à atividade física e à possibilidade de promovê-la em estratos mais desfavorecidos da população, o discurso, aparentemente, não foi repetido.

Por exemplo, os resultados de Reis e Sousa-Mast indicam que:

As iniciativas (...) propostas e executadas pelos diferentes níveis do governo brasileiro, assim como o Cojo, não têm sido percebidas mais amplamente ou tido sucesso em alcançar as pessoas com mais necessidades: as crianças e jovens que vivem em comunidades de baixa renda e, portanto, mais vulneráveis e em situação de risco (35).

No entanto, como dito anteriormente, estudos recentes focados no legado na área de saúde deixados por megaeventos esportivos foram inconclusivos (5). Corroborando essa evidência, um estudo específico realizado em relação a Rio 2016 confirmou a "atual falta de evidências sobre o legado olímpico na promoção da saúde” (36). Apesar disso, o tema da atividade física está presente no relatório inicial para medir os impactos e o legado dos Jogos produzidos pelo Estudo de Impacto dos Jogos Olímpicos - Rio 2016 (37), localizado na parte do relatório sobre a esfera sociocultural, entre outros 22 subtemas. No entanto, atividade física não é um dos principais focos na área de saúde dentro do relatório, que são:

(...) natalidade, expectativa de vida ao nascer, taxa de mortalidade infantil, percentual de leitos hospitalares per capita, percentual de profissionais de saúde per capita e taxa de incidência de dengue no estado do Rio de Janeiro; as despesas do Ministério da Saúde com serviços de saúde per capita em nível federal; e a prevalência do tabagismo em nível municipal (38).

O relatório inclui uma nota que afirma que "a prática de atividade física de pelo menos 150 minutos por semana, de intensidade leve ou moderada; ou, pelo menos 75 minutos de atividade física por semana de intensidade vigorosa" (39) seria o alvo da investigação. Essas orientações seriam usadas pelos autores do relatório, a fim de "monitorar a atividade física, através de um 'índice de atividade física” (39). O relatório destaca uma iniciativa (40) chamada:

Rio em Forma Olímpico, um programa municipal criado em 2009, [que] visa melhorar o acesso à prática esportiva oferecendo atividade física gratuita e de alta qualidade, com apoio de profissionais qualificados, de segunda a sexta-feira, nas áreas urbanas da cidade de Rio de Janeiro. Atualmente, existem mais de 24.000 pessoas que estão sendo atendidas em 436 unidades (41).

No entanto, pouca informação disponível publicamente foi encontrada sobre os efeitos práticos da iniciativa e os instrumentos a serem utilizados a fim de "recomendar práticas" dentro do contexto sugerido pelo relatório. Além disso, o relatório também dá importância à educação física e ao esporte escolar e apresenta uma lista de indicadores a serem observados quando a área é focada:

Carga horária semanal destinada ao esporte nas escolas; percentagem de estudantes que se dedicam à atividade física no contra-turno; número de escolas com instalações esportivas; investimento em equipamento esportivo; relação entre o orçamento e a construção/manutenção de instalações esportivas e equipamentos nas escolas; profissionais de educação física (42).

Não obstante essa ser apenas a primeira versão (o grupo de pesquisa tem como objetivo publicar mais 3 relatórios), o relatório não conseguiu apresentar resultados quanto aos indicadores devido a dificuldades na coleta de dados na esfera federal. Ademais, tem-se apenas uma expectativa de que a parte de monitoramento do relatório realmente se sustente. Além disso, mesmo que esse seja considerado o estudo mais ambicioso no contexto da Rio 2016, sua função principal é somente monitorar estudos a serem realizados por outras instituições. Tal atitude parece ignorar o fato de que "há atualmente uma escassez de estudos bem delineados que sustentem a noção de que sediar os Jogos Olímpicos leve a melhorias na saúde ou um aumento na prática de atividade física e esportiva” (43). Além do que, deixa de considerar a declaração de consenso do Comitê Olímpico Internacional sobre a saúde e aptidão dos jovens através da atividade física e do esporte (44).

Ademais, a literatura sugere que os Jogos em geral "geraram uma percepção negativa na população”, por razôes políticas ou administrativas, que também podem ter, "por sua vez, (...) um efeito negativo sobre a atividade física e, possivelmente, nos níveis de saúde da população" $(5 ; 45)$. Além disso, muitas evidências poderiam estar relacionadas à percepção negativa dos megaeventos esportivos realizados no Brasil e especialmente no Rio de Janeiro (46-49). Consequentemente, pode-se dizer que, além da tendência geral que os 
megaeventos esportivos apresentam de não aumentar os níveis de atividade física, o contexto brasileiro poderia ter tido essa situação agravada pela dimensão, relevância e impacto social das Jornadas de Junho e manifestaçóes posteriores (50).

Ademais, a Rio 2016 parece ser mais uma oportunidade perdida pelos investidores em geral, que insistem em assumir que, pelo simples fato de realizarem um megaevento esportivo (51), a prática esportiva, a atividade física e a saúde melhorariam, e gerariam melhorias de condições de vida, relegando planejamento específico, financiamento e avaliação da área específica para outras partes, ao setor privado ou simplesmente ignorando essa necessidade.

Recentemente, os governos envolvidos nas iniciativas descritas acima e o Cojo aparentemente reduziram seus investimentos na parte de atividade física dos programas e decidiram usar as oportunidades apresentadas para reforçar valores olímpicos e paralímpicos, que são definidos como "excelência, amizade, respeito, coragem, determinação, inspiração e igualdade” (52).

Além disso, o momento não poderia ser mais dramático para o país deixar de aproveitar uma oportunidade com grande potencial que os proponentes de tal ideia sugerem. Em junho de 2015, o Ministério do Esporte brasileiro revelou parte de um ambicioso projeto chamado Diagnóstico Nacional do Esporte. A pesquisa tem como objetivo analisar uma série de fatores relevantes no contexto da prática esportiva, e sua primeira parte trata dos níveis de atividade física da população nacional. No entanto, os resultados não são tão bons quanto se esperava: "Ele revela que quase metade da população entre 14 e 75 anos, cerca de 45,9\%, não pratica qualquer atividade física" (53).

Entretanto, outra indicação de como questôes relacionadas com a saúde pública foram abordadas no contexto dos Jogos Olímpicos Rio 2016 diz respeito, por exemplo, ao tratamento dado às águas que vão acolher as competiçōes de remo. Depois de participar no Campeonato Mundial Júnior de Remo na Lagoa Rodrigo de Freitas, no Rio de Janeiro, um evento de preparação para os Jogos Olímpicos, 13 dos 40 remadores da equipe dos Estados Unidos voltou para casa com problemas de estômago. Os norte-americanos tiveram vômitos e diarreia. A médica Kathryn Ackerman, que foi responsável pela delegação, sugeriu que a contaminação aconteceu devido à poluição da água, que será local das provas da modalidade nos Jogos Olímpicos Rio 2016 (54).

CONCLUSÃO Os dois casos apresentados neste artigo demonstram que, embora o legado de aumento de atividade física seja considerado como uma parte cada vez mais importante dos Jogos Olímpicos, a sua tradução para a prática (ou políticas) ainda é um desafio para os governos, comitês de candidatura, investidores corporativos, organizadores dos Jogos Olímpicos e para o próprio movimento olímpico. Além disso, eles desafiam pesquisadores que procuram estabelecer protocolos, a fim de avaliar as iniciativas de atividade física dentro do contexto dos legados olímpicos.
Uma das primeiras questões a ser considerada é que a atividade física pode receber, e (nos casos estudados) de fato tem recebido, diferentes níveis de ênfase pelos diferentes comitês organizadores dos Jogos, no contexto do papel político mais amplo desempenhado pelo processo de candidatura, planejamento e organização do evento. Além disso, os antecedentes históricos e político-econômicos dos anfitriōes também são cruciais para determinar os resultados desejados de eventos de tal magnitude, incluindo a quantidade de recursos destinados às políticas de aumento de atividade física, seja prática ou retoricamente. Referindo-se ao caso do Brasil, por exemplo, o país também sediou a Copa do Mundo da Fifa 2014, o que certamente teve alguma influência no processo de planejamento do legado olímpico para os Jogos de 2016.

Quanto a esse último, é importante destacar que, enquanto o Reino Unido é uma nação altamente desenvolvida, o Brasil vem lutando para superar dificuldades na maioria das áreas básicas de desenvolvimento humano. Os casos apresentados neste artigo poderiam ser interpretados a partir das diferenças com que a atividade física foi tratada dentro do discurso político. Enquanto para o Reino Unido, com um dos sistemas de saúde mais desenvolvidos do mundo, a atividade física foi central no discurso do legado olímpico e planejamento, para o Brasil não foi dada qualquer atenção séria, uma vez que necessidades mais fundamentais foram enfatizadas em seu lugar.

Considerando especificamente a área de pesquisa, um dos principais desafios a ser superado talvez seja a elaboração de projetos de investigação capazes de medir, avaliar e melhorar a prática de atividade física, chegando a uma boa compreensão dos contornos complexos e mutáveis desses processos enquanto fenômeno social. Também a falta de projetos mais abrangentes e consensuais, a fim de avaliar o legado dos Jogos Olímpicos para o aumento dos níveis de atividade física, pode ser considerado um dos poucos consensos entre os pesquisadores. Isso talvez pudesse ser feito de forma mais conveniente se a promoção da atividade física assumisse um papel mais integrado e proeminente nas propostas de candidatura, planejamento e hospedagem de megaeventos esportivos

Isso leva a pelo menos duas preocupações principais: responsabilização e recursos. Embora o legado tenha se tornado uma constante nos recursos discursivos de megaeventos esportivos e nos Jogos Olímpicos, a promoção da atividade física não é nem unificada nem consolidada dentro dele. Consequentemente, os papéis ainda não são claros e a responsabilidade e prestação de contas é feita de forma difusa entre diversos atores. A implicação prática aqui é que planejamento, promoção, avaliação e financiamento de atividade física também são feitos de forma difusa entre numerosos atores e esse, certamente, é um fator que pode ser considerado como central para o fracasso dos casos analisados aqui. Além disso, parece necessário considerar, a fim de aumentar a eficácia dos legados de atividade física em futuras ediçôes dos Jogos, o desequilíbrio histórico e, aparentemente, onipresente em favor dos esportes de alto rendimento. 
Billy Graeffé professor da Universidade Federal do Rio Grande (FURG) e doutorando na Universidade de Loughborough, Inglaterra. Atualmente suas pesquisas estão focadas em megaeventos esportivos e no esporte internacional.

Joe Piggin éprofessor da Universidade de Loughborough, leciona sobre politicas de esporte e coordena o mestrado em gestão esportiva.

Paul Bretherton defendeu sua tese de doutorado na Universidade de Loughborough sobre a responsabilidade social corporativa e sua relação com os Jogos Olimpicos de 2012, em Londres. Atualmente suas pesquisas estão focadas nas relaçôes entre as Olimpiadas e aspectos ligados à saúde.

$\left.{ }^{*}\right)$ Artigo traduzido por Gilberto Stam do original em inglês.

\section{NOTAS E REFERÊNCIAS}

1. International Olympic Committee. Olympic Charter. 2013a. Disponível em: http://www.olympic.org/Documents/olympic_charter_en.pdf

2. DCMS - Department for Culture, Media and Sport. Before, during and after: Making the most of the London 2012 Games. London. 2008.

3. Idem, p.3.

4. Girginov, V.; Hills, L. "A sustainable sports legacy: creating a link between the London Olympics and sports participation". International Journal of the History of Sport, 25(14), 20910-2116. 2008.

5. Mahtani, K.; Protheroe, J.; Slight, S.; Demarzo, M.; Blakeman, T.; Barton, C.; Brijnath, B.; Roberts, N. "Can the London 2012 Olympics 'inspire a generation' to do more physical or sporting activities? An overview of systematic reviews". BMJ Open, 3(1), pp.e002058. 2013.

6. McCartney, G.; Thomas, S.; Thomson, H.; Scott, J.; Hamilton, V.; HanIon, P.; Morrison, D.S.; Bond, L."The health and socioeconomic impacts of major multi-sport events: systematic review (1978-2008)". British Medical Journal, 340, c2369. 2010.

7. Department for Health. "A systematic review of the evidence base for developing a physical activity and health legacy from the London 2012 Olympic and Paralympic Games". London: DH. 2009b.

8. Kelso, P. "London 2012: Sport England to miss legacy target as games fail to inspire youngsters". The Telegraph. pp.9-10. 2011, dec 8.

9. Gratton, C.; Preuss, H. "Maximizing Olympic impacts by building up legacies". The International Journal of the History of Sport, 25, 1922-1938. 2008.

10. Gibson, O. "Jeremy Hunt admits London 2012 legacy targets will be scrapped". The Guardian. Disponível em: http://www.theguardian. com/sport/2011/mar/28/jeremy-hunt-Iondon2012-legacy. 2011, march 29.

11. Wellings, K.; Datta, J.; Wilkinson, P.; Petticrew, M. “The 2012 Olympics: assessing the public health effect". The Lancet, 378 (9797), 1193-1195. 2011.

12. Cameron, D. Cameron hails Olympics legacy as cabinet meets at site. Online vídeo, 2012. Disponível em: http://www.bbc.co.uk/news/uk-politics-16460572 Acessado em: 9/1/2012.

13. Helm, T. "School sports: Half a million pupils protest against Michael Gove's cuts". The Guardian,2010, December 5. Disponível em: http:// www.theguardian.com/education/2010/dec/05/school-sport-partnerships-protests-michael-gove
14. Department for Health. The public health responsibility deal. London: DH. 2011.

15. Smith, A.C.T.; Westerbeek, H.M. "Sport as a vehicle for deploying corporate social responsibility". Journal of Corporate Citizenship, 25, 43-54. 2007.

16. Johnson, B. "London 2012 Olympics: London and Team GB - take a bow. You've dazzled the world". The Telegraph. 2012, Aug 12.

17. UK Government \& Mayor of London. "Inspire by 2012: The legacy from the London 2012 Olympic and Paralympic Games". London: UK Government \& Mayor of London. p.22. 2013.

18. UK Government \& Mayor of London, 2013, Op. Cit.

19. Idem, p.25.

20. Maranhão, R. "Com reforço de Lula, 'seleção' brasileira usa a emoção na cartada final por 2016". 2 de outubro de 2009, Globo Esporte.com. 2009.

21. Aquino, Y. "Lula: Olimpíadas serão oportunidade única para o Brasil". 2 de outubro de 2009. Rede Brasil Atual. 2009.

22. Darnell, S. C. "Mega sport for all? Assessing the development promises of Rio 2016". In: Rethinking matters Olympic: investigations into the socio-cultural study of the modern Olympic movement, 10th International Symposium for Olympic Research (pp. 498-507). 2010.

23. Viga, R.; Bulcão Pinheiro, L. "Dilma visita COB e ganha agasalho de equipe brasileira". 2 de agosto de 2010.13 de setembro de 2009. Portal Terra, especial Jogos Olímpicos 2016. 2010.

24. Previdelli, A. "O plano do Brasil para ganhar medalhas nas Olimpíadas". Exame online. 2012

25. Ministério do Esporte Plano Brasil Medalhas 2016. Disponível em: http://www.esporte.gov.br/index.php/institucional/alto-rendimento/ plano-brasil-medalhas [Acessado em 19 outubro 2015]. 2012.

26. Brasil. Dossiê de candidatura. Disponível em: http://www.rio2016.com/sites/default/files/parceiros/dossie_de_ candidatura_v1.pdf [Acessado: em 9 outubro 2015]. 2009.

27. Rio 2016. "Rio 2016 ${ }^{\mathrm{TM}}$ comemora marco de três anos para os Jogos de olho na educação". 6 de agosto de 2015. Site do Comitê Olímpico Rio 2016. 2013.

28. Rio 2016. “Transforma, programa de educação Rio 2016, é ampliado e vai chegar a 19 municípios do Rio". 4 de março de 2015. Site do Comitê Olímpico Rio 2016. 2015.

29. Reis, A.; de Sousa-Mast, F.; Gurgel, L. "Rio 2016 and the sport participation legacies". Leisure Studies, 33(5), pp.437-453. 2013.

30. Idem, p.449.

31. Rio 2016. "Projeto das Olimpíadas Escolares é apresentado em congresso mundial". 31 de agosto de 2012. Site do Comitê Olímpico Rio 2016. 2015.

32. Brum, A. "Sonho do top 10 no Rio faz Brasil se curvar a gringos". Gazeta do Povo. 4 de janeiro de 2014.

33. Hogan, K.; Norton, K. "The 'price' of Olympic gold". Journal of Science and Medicine in Sport 3 (2): 203-218. 2000.

34. Chahad, A. "Sim, nós podemos e vamos realizar essa Olimpíada", diz Lula. Portal Terra: Esportes. 1 de outubro de 2009. 
35. Reis, A. C.; Sousa-Mast, F. R. "Rio 2016 and sport legacies. The legacies of the Olympic Games for youth at-risk in Rio de Janeiro". (IOC Olympic Studies Centre Postgraduate. Research Grant Programme 2012). 2012.

36. Demarzo, M. M. P.; Mahtani, K. R.; Slight, S. P.; Barton, C. A.; Blakeman T.; Protheroe, J. "The Olympic legacy for Brazil: is it a public health issue?". Cad. Saúde Pública, Rio de Janeiro, 30 (1): 8-10, jan, 2014.

37. OGI 2016, The OGI - Sage/Coppe/UFRJ Research team for: the organising committee for the Rio 2016 Olympic and Paralympic Games (Rio $2016^{\mathrm{TM}}$ ). Olympic Games Impact (OGI) Study - Rio 2016 Initial report to measure the impacts and the legacy of the Rio 2016 Games. 2014.

38. Idem, p.124.

39. OGI 2016, 2014. Op.cit. p.137.

40. http://www.rioemformaolimpico.com.br

41. OGI 2016, 2014. Op.cit. p.139.

42. Idem, p.140.

43. Demarzo et al, 2014. Op.Cit. p.9.

44. Mountjoy, M. et al. "International Olympic Committee consensus statement on the health and fitness of young people through physicalactivity and sport". British Journal of Sports Medicine, 45(11), pp.839-848. 2011.

45. Demarzo et al, 2014. Op.Cit. p.8.

46. Saad-Filho, A.." Mass protests under 'left neoliberalism': Brazil, june-july 2013". Critical Sociology, 39 (5), pp.657-669. 2013.

47. Saad-Filho, A.; Morais, L. "Mass protests: Brazilian spring or Brazilian malaise?". Socialist Register, v.50. 2014.

48. Braga, R.. "As jornadas de junho no Brasil: crônica de um mês inesquecível". Observatorio Social de América Latina (Osal), año XIV nº.34. Clacso. 2013.

49. Ruediger, M.; de Souza, R.; Grassi, A.; Ventura, T.; Ruediger, T. “June Journeys in Brazil: from the networks to the streets". Social Science Research Network (SSRN). 2014.

50. Harvey, D.; Vainer, C.; Zizek, S. et. al. Cidades rebeldes : Passe Livre e as manifestações que tomaram as ruas do Brasil. Boitempo Editorial, São Paulo, 2013.

51. Murphy, N. M.; Bauman, A. "Mass sporting and physical activity events: are they bread and circuses or public health interventions to increase population levels of physical activity?" Journal of Physical Activity and Health, 4. pp. 193-202. 2007.

52. Rio 2016. Rio 2016 video festival spreads Olympic and Paralympic values in city's schools. 2013b. Disponível em: <http://www.rio2016. com/en/news/news/rio-2016-video-festival-spreads olympic-and-paralympic-values-in-citys-schools >.[Acessado 17 outubro 2015].

53. Portal Brasil. Diagnóstico Nacional do Esporte mapeia atividade física. 2015. Disponível online.

54. Zero Hora. "Treze atletas americanos adoecem após evento-teste de remo no Rio". 10 de agosto de 215, jornal Zero Hora online: ZH Olimpíada 2016.2015.

\section{VALORES ASSOGIADOS AOS JOCOS OLIMPICOS*}

\author{
Holger Preuss \\ Norbert Schütte \\ Thomas Könecke \\ Lamartine DaCosta \\ Tradução de Gilberto Stam
}

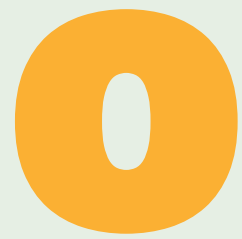

movimento olímpico vem passando por transformaçōes ao longo dos anos. Essas ocorrem de maneira lenta, porém constante. $\mathrm{O}$ ambiente social e cultural muda com o tempo e, dessa forma, a percepção dos valores olímpicos não é estável (1). A entidade principal do movimento olímpico são os Jogos Olímpicos. Há alguns anos, discutimos se os valores associados aos Jogos Olímpicos estão se alterando. Os Jogos devem ser atraentes aos jovens para que sejam vistos como mágicos e despertem o interesse geral. No entanto, em muitas cidades europeias, nos últimos anos, os referendos públicos sobre sediar os Jogos Olímpicos demonstraram que as populaçōes locais não querem receber esses eventos em suas cidades. O presidente do Comitê Olímpico Internacional (COI), Thomas Bach, percebeu isso e começou uma reforma, chamada Agenda 2020.

No início do milênio, Milton-Smith (2) reconheceu uma crítica aos Jogos Olímpicos que refletia o fracasso das principais instituições globais em lidar com as consequências sociais e éticas da globalização, muitas vezes incluindo questôes ambientais e o terrorismo. Isso levou a uma desilusão generalizada com os Jogos Olímpicos. Atualmente, os Jogos parecem espelhar o desencanto com os valores "modernos" da globalização, incluindo vencer a qualquer preço (uso do doping), comercialização, intensa rivalidade entre países, nepotismo (na preparação dos Jogos), trapaça (arranjo de resultados), corrupção e vantagem competitiva das nações altamente desenvolvidas e recém-industrializadas sobre as demais (3).

O objetivo deste artigo é lançar luz sobre a estrutura e o significado dos valores que são associados aos Jogos Olímpicos por meio de uma pesquisa com pesquisadores e profissionais que, embora especialistas nesses eventos, não dependem do sistema olímpico para desenvolverem suas atividades.

A INVESTIGAÇÃO SOBRE OS VALORES OLÍMPICOS Um dos estudos básicos sobre os valores olímpicos foi conduzida pelo filósofo alemão Hans Lenk (4). Ele identificou muitos dos valores que hoje aparecem na Carta Olímpica (5). Outras pesquisas importantes foram realizadas por Parry (6), que não só identificou os dez valores que caracterizam os Jogos Olímpicos, mas também comparou-os com os valores dos Jogos da Grécia Antiga. A fazer isso, ele identificou o 